\title{
AdVANCING STUdent Motivation ANd COURSE InTEReST THROUGH A UTILITY VALUE INTERVENTION IN AN ENGINEERING DESIGN CONTEXT
}

\author{
Staci A. Turoski ${ }^{1}$ and William J. Schell ${ }^{1,2}$ \\ Montana State University ${ }^{1}$ Norm Asbjornson College of Engineering \\ and ${ }^{2}$ Montana Engineering Education Research Center \\ staci.turoski@montana.edu
}

\begin{abstract}
Understanding and improving student motivation is critical for educators because motivation is essential for academic success. Student motivation is multifaceted and complex with interest as one of many factors related to motivation and motived behavior. Student interest in course material can be supported by helping them understand the value and relevance of the material to their life. Within an expectancy-value framework, one aspect for understanding students perceived task value is to assess their perception of the utility value, or their view of the usefulness, of the task to their present or future goals. One way to encourage value is to have students write about the relevance of the course material to their life through structed utility value interventions. This study will compare the performance, interest, and motivation between students who participated in structured utility value interventions and those in a control group who did not during a third year multidisciplinary engineering design course. Initial indications are that students' interest and motivation increase when given the utility value intervention.
\end{abstract}

Keywords: engineering education, engineering design, multi-disciplinary, utility value, student motivation

\section{INTRODUCTION}

Engineering educators face many challenges; whether it's keeping up with fast-paced changing technology, improving pedagogical methods, or remaining committed to teaching engineering fundamentals, there is no shortage of demands on faculty time. One common thread in these challenges is how educators motivate students and encourage them to maintain interest in a course. One way to encourage interest is to help students understand the value and relevance of the material to their lives.

Recent research has shown simple writing interventions prompting students to understand the usefulness of the material can increase both interest and student performance
[10]. Advantages to simple writing interventions are that they require relatively little classroom or student time and can be adapted to almost any course.

Helping students connect value and relevance to the course material can be particularly important in an engineering design context. ABET asserts the fundamentals of the engineering design process are the establishment of objectives and criteria, synthesis, analysis, construction, testing, and evaluation [1]. This decision-making process is often an iterative application of science and math fundamentals applied to meet stated objectives. It is essential for engineering educators to help students understand the relevance and importance of learning engineering design.

This study focuses on engineering students' perception of value in learning the design process in a multidisciplinary context. When students see value in what they are learning, they are more likely to engage in the course, attend class and increase effort. These are key contributors to motivation.

\section{BACKGROUND AND LITERTURE}

There are many motivational theories situated in an educational framework, examples include selfdetermination theory [5], attribution [17], and self-efficacy [4]. One established, and widely used, perspective on motivation is Expectancy-Value Theory [6]. In this theory, student motivation is determined by success expectancies and perceived task value.

\subsection{Expectancy-Value Theory}

Theorists in this domain argue that, "an individuals' choice, persistence, and performance can be explained by their beliefs about how well they will do the activity and the extent to which they value the activity" [19]. As indicated by the name, this theory is comprised of two primary components. The expectancy component addresses individuals' current beliefs about their ability to 
complete a task or their belief in their ability to complete a task in the future. In an educational setting, when students feel like they can do the assigned task, they are more likely to engage in that task. The value component addresses the value individuals place on the task in relation to achieving current or future goals. From a task value perspective, when students value a task, or see the relevance of the task to their goals, they are also more likely to engage in the task.

Building on previous research [3], Eccles and colleagues proposed four distinct reasons for an individuals' perception of task value [6]. The first is interest value or the enjoyment received from engaging in a task. Second is the utility value or the usefulness of the task related to achieving current or future goals. The third is attainment value, which suggests the completion of the task is relevant to an important value held by the individual. The fourth value is the cost of engaging in the task. In this context, cost is composed of the amount of effort, time and possibility of failure.

This study focuses on the component of utility value. Students' perceived utility value of a task and their willingness to engage in a task is directly linked to their perception of how the task will fulfill their current (e.g. class grades) and future (e.g. career) goals [12]. Recent research into understanding these constructs created a scale for measuring subjective task utility value [11].

\subsection{Effective Student Motivation Interventions}

Multiple experimental studies found that when students see value in their course material, they work harder, perform better, and are more likely to keep pursuing the topic $[8,11,18]$. Prior research shows the effectiveness of a simple intervention used to promote perceived utility value that asks students to write about the relevance of the course material to their lives. These simple writing interventions, where students are connecting material to their future careers, have proven most beneficial for low performing students. Research also suggests that when utility value interventions are implemented into the curriculum, interest improves because students are making connections on a more frequent basis [12].

In a recent meta-analysis of intervention studies grounded in motivation theory, Lazowski and Hulleman [14] found motivation interventions are overall effective at enhancing educational outcomes. Through analysis of 74 published and un-published papers, 15 different motivation theories were reviewed. The meta-analysis provides insight between motivational constructs and educational outcomes and serve as guide to educators seeking to improve motivation and learning outcomes. One key finding from the analysis runs contrast to expensive and time-consuming comprehensive school reform: motivation interventions cost little or no money, require minimal time to deliver, and can be implemented across a wide variety of very different educational contexts [13].
A conceptual model for designing interventions in higher education was developed by Harackiewicz and Priniski [9]. The model includes three steps:

1. assessment of a problem

2. designing and conducting an appropriate intervention

3. assessing targeted outcomes

The study differentiated three types of interventions:

- those focused on how students perceive value in academic tasks

- interventions that change the way students frame academic tasks

- those focused on students' personal values

Each of these three intervention types are studentcentered and aim to engage students in some form of reflective practice either through writing or conversation.

This study uses the intervention type focused on how students perceive value in academic tasks as it relates to learning the engineering design process and its application to future careers. This type of intervention has been found to enhance students' interest and performance by helping students make sense of their academic experiences.

\subsection{Study Overview}

Harackiewicz and Priniski's [9] framework is utilized in the design of this study. Specific utility value interventions were adapted to encourage students to connect the relevance of the course material to their future careers. The outcomes of the intervention will be assessed through student performance and interest in the course. This study aims to answer several research questions:

RQ1. Does a utility value intervention influence student interest in a multidisciplinary engineering design course?

RQ2. Does a utility value intervention influence student performance in a multidisciplinary engineering design course?

RQ3. Do utility value interventions impact low performing students' interest differently than other students?

RQ4. Do utility value interventions impact low performing students' performance differently than other students?

RQ5. Do utility value interventions increase the frequency at which students connect course material to their future careers?

RQ6. Do utility value interventions increase the frequency for students closer to graduation to connect course material to their future careers?

The answers to these questions will help inform engineering educators on the perception of value in 
learning the engineering design process, the interest level during the course, and the effect of simple writing interventions. Specific methodology, analysis approach, and initial results are covered in the following sections.

\section{METHODOLOGY}

This study employs an experimental research approach and utilizes quantitative survey research to understand impacts. Experimental research methods are deployed to understand the difference between the treatment and control groups [15]. Survey research methods are used to measure interest in the course, expectancy, utility value, cost, and frequency of connections. Data from each measure specifically enables answering the research questions. Specific measures and methods are discussed in later sections.

A pretest-posttest control group design was used to examine the effects of a utility value intervention on student interest and performance in the course [7]. Both groups were administered a pretest survey. Following the pretest, the experimental group received the motivation intervention while the control group experienced an assignment of similar duration, without the focus on motivation. At appropriate point toward the end of the semester, both groups were administered the same posttest. Figure 1 provides an overall schedule.

Intervention $1 \quad$ Intervention $2 \quad$ Intervention 3

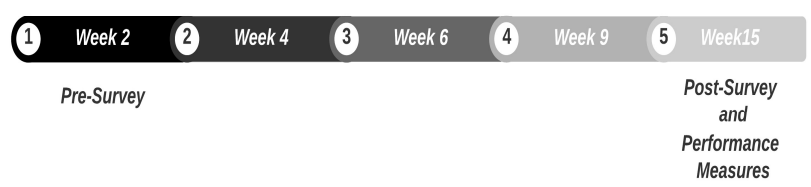

Fig. 1. Overall schedule.

The dependent variables for the study are student interest in the course and academic performance on two assignments. The independent variables are the treatment condition, motivation measures, time to graduation, low performing students, and other demographic measures. The following sections explore the participants and each of the measures and related instruments.

\subsection{Participants and Experimental Design}

Participants were chosen for the study based on enrollment in a 15-week large engineering design multidisciplinary course at Montana State University during Spring 2020. The course is taught over eight sections with four different instructors each teaching two sections. Total enrollment for the course is 350 students for the semester of the intervention. This study considers only four of the eight sections, taught by two different instructors. The four sections were selected based on instructor engagement in the study. Table 1 summarizes the four sections and their underlying characteristics. The selection of students for the control and treatment groups are largely based on time of class and instructor. Since each instructor teaches two sections, each instructor has both a treatment and control group, an attempt to reduce any potential bias in the data. Previous experience teaching the course and average class GPA, indicates the 8:00am section is generally the lowest performing, so it was selected for the intervention, given that the literature shows motivation interventions provide more benefit to low performing students.

Table 1: Experiment Design and Historical GPA.

\begin{tabular}{ccccc}
\hline Time & $\boldsymbol{n}$ & Test & Instructor & $\begin{array}{c}\text { Average } \\
\text { GPA }\end{array}$ \\
\hline $8: 00$ & 42 & Yes & 1 & 3.11 \\
$9: 00$ & 44 & No & 1 & 3.38 \\
$10: 00$ & 45 & No & 2 & 3.29 \\
$11: 00$ & 43 & Yes & 2 & 3.28 \\
\hline
\end{tabular}

\subsection{Dependent Variables}

The three dependent variables in the study are interest, course performance, and frequency of connections. Interest in the course is measured on an 8-item scale adapted from previous work by Hulleman [12]. An example item is "I think the engineering design process is very interesting. I am excited about this class,". Participants responded to survey items using an 8-point Likert scale ranging from completely disagree to completely agree. The interest measures were taken during Week 2 and Week 15. For subsequent analysis, interest was treated like a continuous variable as is common practice in the literature [13]. Using data from a previous pilot study, factor analysis was performed on the interest measure. That analysis found that interest loaded on two factors: interest in the course and interest in the engineering design process. This split in the interest factor loading was confirmed with the pre-test analysis of interest. Four items loaded on each interest measure.

The second dependent variable is course performance. Course performance is measured using two assignments during the semester. The first assignment is an analytical essay where students write about a case study of their choosing within the parameters of engineering design. A specific rubric is used to assess this assignment and promote consistency of measurement. The second assignment asks students to recap their design process experience through a visual depiction. Again, this assignment is assessed using a standardized rubric.

The final dependent variable, connection frequency, is used to understand if students are making connections between the course material and their future careers. This measure uses a 3-item scale. An example item is "During 
a regular class period or lecture, how often do you connect the class material to your future career?" [12]. The instrument uses a 6-point Likert scale from Never to All of the Time. The frequency of connection measure is taken only at the end of the semester.

\subsection{Independent Variables}

The main independent variable for this study is the treatment condition of completing the utility value intervention (treatment population) or not completing the intervention (control population). This independent variable captures whether students write to the summative response (control) or to the more reflective prompt (experimental). Method of instruction, learning environment, and length/frequency of treatment remain the same [15]. These controls are ensured by utilizing four sections of the same course taught in the same semester without varying curriculum or timeline.

A three-item measure is used for student motivation. The three items used to measure motivation are expectancy, utility value, and cost. This had been used in previous studies $[2,12,16]$. Expectancy is measured on a 4-item scale. An example item is "I am confident that I will be successful in this class." Utility value is measured on a 6-item scale. An example item is, "The course material is relevant to my future career plans." Cost is measured on a 5-item scale. An example item is, "I am unable to invest the effort that is needed to do well in this class." These items were adapted from a scale used in Hulleman, et al. [12]. Participants will respond to survey items using an 8point Likert scale ranging from Completely Disagree to Completely Agree. These measures will be taken during Week 2 and Week 15.

The final two independent variables involve identifying low performing students and comparing how their interest and performance levels change compared to other students. Low performing students are identified by looking at math, chemistry, physics, and engineering courses students completed prior to the semester of intervention. Data provided by Montana State's Office of Planning and Analysis was used to identify the population. The sample population includes 12 different majors each taking a slightly different course load. Equivalent courses will be compared when possible. Low performing students are defined as those that are one standard deviation below the mean.

In addition to the university data, participants were asked to self-report age, gender, and discipline. Table 2 provides a summary of this information.
Table 2: Comparison of Key Measures for Treatment and Control Groups.

\begin{tabular}{lccc}
\hline \multicolumn{1}{c}{ Variables } & Control & Treatment & All \\
\hline Mean Age (years) & 21.5 & 21.9 & 21.6 \\
Mean GPA & 3.34 & 3.20 & 3.28 \\
Gender & & & \\
$\quad$ Male & 62 & 66 & 128 \\
Female & 27 & 18 & 45 \\
Other & 0 & 1 & 1 \\
Discipline & & & \\
Civil Eng. & 15 & 11 & 26 \\
Chemical Eng. & 12 & 6 & 18 \\
Mechanical Eng. & 27 & 33 & 60 \\
Other & 35 & 35 & 70 \\
\hline
\end{tabular}

\subsection{Intervention Prompts}

Three different times during the semester students were asked to write to their specific group prompt after the completion of a given milestone in the design process. The control group participants received the following prompt: "In the space below, summarize the what you know about the Discover Phase of Engineering Design Process in 3-4 paragraphs. We are not asking you to elaborate on the material, just to summarize the information that you can recall." The utility value treatment group received the prompt: "In the space below, write in 3-4 paragraphs how the material you have been studying in the Discover Phase of the Engineering Design Process relates to your future career. We are not asking you to summarize the material, just to elaborate on its relevance to your future career." These prompts were adapted from previous validated utility intervention studies $[10,12]$.

\subsection{Initial Analysis}

Initial factor analysis on the pre-survey items confirmed the presence of the three motivation factors along with reliability measures: expectancy, utility value, and cost. Factor analysis indicated two separate factors for interest: interest in the course and interest in the design process. Results are summarized in Table 3.

Table 3: Descriptive Statistics for Pre-survey Items.

\begin{tabular}{|c|c|c|c|c|}
\hline Variable & $N$ & Mean & SD & $\alpha$ \\
\hline Expectancy & 165 & 28.21 & 3.82 & 0.90 \\
\hline Utility Value & 165 & 36.95 & 6.84 & 0.92 \\
\hline Cost & 165 & 17.76 & 6.42 & 0.85 \\
\hline $\begin{array}{l}\text { Interest in } \\
\text { Course }\end{array}$ & 164 & 24.71 & 4.69 & 0.93 \\
\hline $\begin{array}{l}\text { Interest in } \\
\text { Design Process }\end{array}$ & 166 & 22.05 & 5.76 & 0.92 \\
\hline
\end{tabular}


Analysis will be conducted on the post-intervention survey to confirm the presence of the intended factors. Reliability estimates using Cronbach's alpha will be used. Multivariate regression analysis will occur after postintervention measures are available.

Brief qualitative analysis will be done on the content of the responses to the prompt. A cursory analysis of the content difference between the two groups will give insight to the way students responded to the prompts. Further information may be gathered specifically from the relevance prompt to gauge the level that students are making connections to their future careers.

The experimental research approach utilizes quantitative survey research to understand impacts. These methods facilitate understanding the difference between the two groups. Data from each measure specifically supports answering the research questions summarized in Table 4.

Table 4: Research questions associated to measures.

\begin{tabular}{ccc}
\hline $\begin{array}{c}\text { Research } \\
\text { Questions }\end{array}$ & \multicolumn{2}{c}{ Variables } \\
& Independent & Dependant \\
\hline RQ1 & Treatment, & Course Interest, \\
& $\begin{array}{c}\text { Expectancy, Cost, } \\
\text { Utility Value } \\
\text { Treatment, } \\
\text { RQ2 } \\
\text { Expectancy, Cost, }\end{array}$ & Pesign Process Interest \\
& Utility Value \\
RQ3 & Treatment, \\
& Expectancy, Cost, & Course Interest, \\
& Design Process Interest \\
Utility Value & \\
RQ4 & Treatment, \\
& Expectancy, Cost, & Performance \\
Utility Value & \\
RQ5 & Treatment & Frequency \\
& Treatment, Class & Frequency \\
\hline
\end{tabular}

\section{EXPECTED OUTCOMES}

As of this writing, all data collection was recently completed according to the research plan. Work to analyze the responses and performance measures is underway and will be presented later.

Based on previous research, student interest in the course material will likely increase. It will be of significance to understand to what extent, if any, interest changes between the treatment and control groups. It is anticipated interest will increase for the treatment group, but it is also possible in the control group.

Final interest in the course will also be compared to the pilot study conducted the previous semester. It is likely the final interest measures will be similar in the control group. Previous research did not differentiate the two factors in interest so it is not known how or if those measures will change.

Student performance measures are expected to be higher in the treatment groups. Historically, students enrolled in the 8:00 class period have had the lowest overall course grades as well as the lowest overall GPA of any other class. Using this section as a treatment group could have potential impacts to raise interest, and therefore, performance outcomes.

In accordance with previous research [12], it is anticipated low performing students will see the largest performance and interest gains, again, this may be especially evident in the 8:00 class. GPA analysis will support the identification of low performing students prior to enrollment in the engineering design course.

\section{CONCLUSION AND FUTURE WORK}

This paper presents a plan to deepen our understanding of student perceptions of value in the engineering design process. It also outlines how interventions designed to help students think beyond the classroom into the future as engineers can be tested. This research has potential to help instructors tap into intrinsic motivation in students to see the application of course material beyond the classroom. The configuration of this intervention program for engineering design students is meaningful because it can shed light on how to motivate and keep students engaged.

\section{Acknowledgements}

We greatly appreciate the support and contribution from Mandy Rutherford as a member of the course teaching team and the KEEN Network for inspiration and tools to aid the execution of this study.

\section{References}

ABET. "Accreditation Criteria and Supporting Documents."

https://www.abet.org/accreditation/accreditationcriteria/ (accessed April 17, 2019).

[2] Mete Akcaoglu, Joshua M Rosenberg, John Ranellucci, and Christina V Schwarz, "Outcomes from a self-generated utility value intervention on fifth and sixth-grade students' value and interest in science," International Journal of Educational Research, vol. 87, pp. 67-77, 2018.

[3] John W Atkinson, "Motives in fantasy, action, and society: A method of assessment and study," 1958.

[4] Albert Bandura, "Social foundations of thought and action: a Social Cognitive Theory," ed: Prentice-Hall, Englewood Cliffs, NJ, 1986.

[5] Edward L Deci and Richard M Ryan, "The general causality orientations scale: Self- 
determination in personality," Journal of research in personality, vol. 19, no. 2, pp. 109-134, 1985.

[6] Jacquelynne S Eccles et al., in Achievement and achievement motivation: psychological and sociological approaches, 1983, ch. Expectancies, values and academic behaviors pp. 75-146.

[7] Lorrie R Gay and Geoffrey E Mills, Educational research: Competencies for analysis and applications, student value edition, 11 th ed. Pearson, 2011.

[8] Judith M Harackiewicz, Amanda M Durik, Kenneth E Barron, Lisa Linnenbrink-Garcia, and John M Tauer, "The role of achievement goals in the development of interest: Reciprocal relations between achievement goals, interest, and performance," Journal of educational psychology, vol. 100, no. 1, p. 105, 2008.

[9] Judith M Harackiewicz and Stacy J Priniski, "Improving student outcomes in higher education: The science of targeted intervention," Annual review of psychology, vol. 69, 2018.

[10] Chris Hulleman, Olga Godes, Bryan Hendricks, and Judith Harackiewicz, "Enhancing Interest and Performance With a Utility Value Intervention," Journal of Educational Psychology, vol. 102, pp. 880-895, 11/01 2010, doi: 10.1037/a0019506.

[11] Chris S Hulleman, Amanda M Durik, Shaun B Schweigert, and Judith M Harackiewicz, "Task values, achievement goals, and interest: An integrative analysis," Journal of educational psychology, vol. 100, no. 2, p. 398, 2008.

[12] Chris S Hulleman, Jeff J Kosovich, Kenneth E Barron, and David B Daniel, "Making connections: Replicating and extending the utility value intervention in the classroom," Journal of Educational Psychology, vol. 109, no. 3, p. 387, 2017.

[13] Susan Jamieson, "Likert scales: how to (ab) use them," Medical education, vol. 38, no. 12, pp. 1217-1218, 2004.

[14] Rory A Lazowski and Chris S Hulleman, "Motivation interventions in education: A metaanalytic review," Review of Educational research, vol. 86, no. 2, pp. 602-640, 2016.

[15] Geoffrey E Mills and Lorraine R Gay, Educational research: Competencies for analysis and applications, Eleventh Edition ed. Pearson, 2016.

[16] Dajung Diane Shin et al., "Science for all: Boosting the science motivation of elementary school students with utility value intervention," Learning and Instruction, vol. 60, pp. 104-116, 2019.

[17] Bernard Weiner, "May I borrow your class notes? An attributional analysis of judgments of help giving in an achievement-related context," Journal of Educational Psychology, vol. 72, no. 5, p. 676, 1980.

[18] Allan Wigfield, "Expectancy-value theory of achievement motivation: A developmental perspective," Educational psychology review, vol. 6, no. 1, pp. 49-78, 1994.

[19] Allan Wigfield and Jacquelynne S Eccles, "Expectancy-value theory of achievement motivation," Contemporary educational psychology, vol. 25, no. 1, pp. 68-81, 2000. 